\title{
Comparison of FK506 (Tacrolimus) and Glucocorticoid Ointment on Dermal Atrophogenicity in Rats
}

\author{
Akihiko Hisatomi, Takashi Mitamura, Mamoru Kimura, Yuji Oishi, Toshiyuki Fujii, and Kaname \\ Ohara
}

Toxicology Research Laboratories, Fujisawa Pharmaceutical Co., Ltd.

\begin{abstract}
FK506 (Tacrolimus) is a potent immunosuppressive agent and its ointment formulation was shown to be effective on atopic dermatitis in a clinical study. As atrophy of the skin is one of the adverse effects of dermal application of such drugs as glucocorticoid ointment, the aim of the present study was to investigate whether FK506 ointment induces skin atrophy in rats.

0.3\% FK 506 ointment treatment did not induce skin atrophy at the application site when applied daily for 3 weeks to rats. In contrast, glucocorticoid ointments such as $0.05 \%$ clobetasol 17 -propionate (CP: Dermovate $\left.{ }^{\circledR}\right), 0.12 \%$ betamethasone 17 -

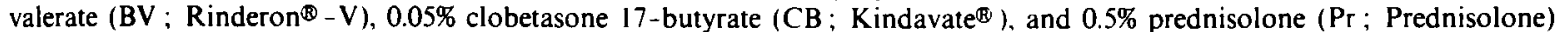
elicited skin atrophy, and histopathologically decreased subcutaneous adipose tissue, and caused thinning of the epidermis and dermis. Furthermore, staining by proliferating cell nuclear antigen (PCNA) showed that these glucocorticoid ointments led to suppression of epidermal cell proliferation, and their potency in descending manner was $C P>P r>C B>B V$.

In conclusion, it was clearly established that FK506 does not induce skin atrophy, which is one of the characteristic dermal toxicities of glucocorticoid ointments. The drug is therefore expected to be well tolerated for long term application in skin deseases. (J Toxicol Pathol 1997; 10: 97 102)
\end{abstract}

Key words : FK506 (Tacrolimus), Glucocorticoid, Dermal atrophogenicity

\section{Introduction}

FK 506 is a new macrolide immunosuppressant extracted from streptomyces tsukubaensis ${ }^{1}$. The pharmacological mechanism of FK506 is similar to that of cyclosporine A (CsA), but its action is approximately 100 times more potent than that of CsA in vitro assay ${ }^{2}$. Clinically, FK506 is reported to suppress rejection of renal and liver allografts ${ }^{3,4.5}$, and has also been shown to be effective in such autoimmune diseases as asthma and rheumatoid arthritis. Another of the cited target diseases for use of FK506 is atopic dermatitis, and Nakagawa et al. $^{6}$ have reported that FK506 ointment also has a satisfactory effect in this field. On the other hand, while adrenocortical hormone (glucocorticoid) ointments are in general use for atopic diseases and their marked efficacy has been established, their use is sometimes restricted owing to local side effects such as skin atrophy, redness and telangiectasia ${ }^{7,8,9}$. In this connection, though many investigators have reported that glucocorticoid ointments elicit skin atrophy in experimental animals including rats ${ }^{10,11,12}$, the topical side effects of FK506 ointment have not been investigated in detail. In this paper, we report on the dermal atrophogenicity (skin thickness, weight, and morphology) of FK506 ointment in rats subjected to 3 weeks of daily application of the drug.

\footnotetext{
久富晃彦 三田村孝 木村 守 大石裕司 藤井登志之 小原 要

Accepted for publication: February 20, 1997

Mailing address: Akihiko Hisatomi, Toxicology Research Laboratories, Fujisawa Pharmaceutical Co., Ltd. 1-6, 2-Chome, Kashima. Yodogawa-ku, Osaka 532, Japan.
}

\section{Materials and Methods}

\section{Materials}

Male Jcl : SD strain rats (3-week old) were purchased from Clea Japan Inc (Tokyo, Japan). Four-week old rats weighing 105-132 $\mathrm{g}$ were used after acclimation for 1 week. During the acclimation and study, the animals were kept in a controlled environment of $23 \pm 1{ }^{\circ} \mathrm{C}$ temperature, 12-hour light/12-hour dark cycle, $55 \pm 5 \%$ relative humidity, and 14 20 times/hour ventilation. The animals were allowed free access to laboratory standard diet and tap water.

0.3\% FK506 ointment was prepared by Fujisawa Pharmaceutical Co. Ltd (Osaka, Japan). The reference drugs were four glucocorticoid ointments : $0.05 \%$ clobetasol 17 propionate(CP) ointment (Dermovate ${ }^{\circledR}$; Nippon Glaxo Ltd., Tokyo, Japan), $0.12 \%$ betamethasone 17 -valerate (BV) ointment (Rinderon ${ }^{\circledR}-\mathrm{V}$; Shionogi \& Co. Ltd., Osaka, Japan), 0.05\% clobetasone 17-butyrate (CB) ointment (Kindavate ${ }^{\circledR}$; Nippon Glaxo Ltd.), and $0.5 \%$ prednisolone (Pr) ointment (Prednisolone ointment Maruishi; Maruishi Pharmaceutical Co. Ltd., Osaka, Japan.). These ointments were selected according to strength of efficacy ${ }^{13}$. In short, CP, BV, $\mathrm{CB}$, and $\mathrm{Pr}$ ointments were strongest, strong, medium, and weak, respectively.

\section{Methods}

$0.2 \mathrm{~g}$ of test ointment was applied for 6 hours daily to the shaven dorsolumbar skin $(3 \times 3$ centimeters towards pelvic limb from the midline between thoracic limb and pelvic limb) of 7 rats each for 21 consecutive days. Each animal was weared with 'Elizabethan' collar prior to application of test substance. After 6 hours, the test substance was removed by washing with a wet raw cotton. A sham control group 
was also provided. All the rats were weighed, and skin thickness of the topical site was measured prior to the first dosing and subsequently at weekly intervals throughout the study. Skin thickness was measured according to the double skin-fold thickness method by a dial thickness gauge $(\mathrm{C}-107$, Citizen Watch Co Ltd., Tokyo, Japan.). Average in thickness was calculated from two values excluded the maximum and minimum values in four measurements.

The day after the conclusion of ointment application, all the animals were euthanized by exsanguination under ether anesthesia, and the dorsal skin was removed, disc-punched ( 3 centimeters in diameter) and weighed.

The skin discs were held between two filter papers, fixed in phosphate-buffered $10 \%$ formalin for just 72 hours, embedded in paraffin, sectioned, and stained with hematoxylin and eosin (HE).

PCNA immunostaining was performed in other sections after deparaffination and incubated with anti-PCNA mouse antibody (PC-10, Novacastra Newcastle upon Tyne, U.K.,

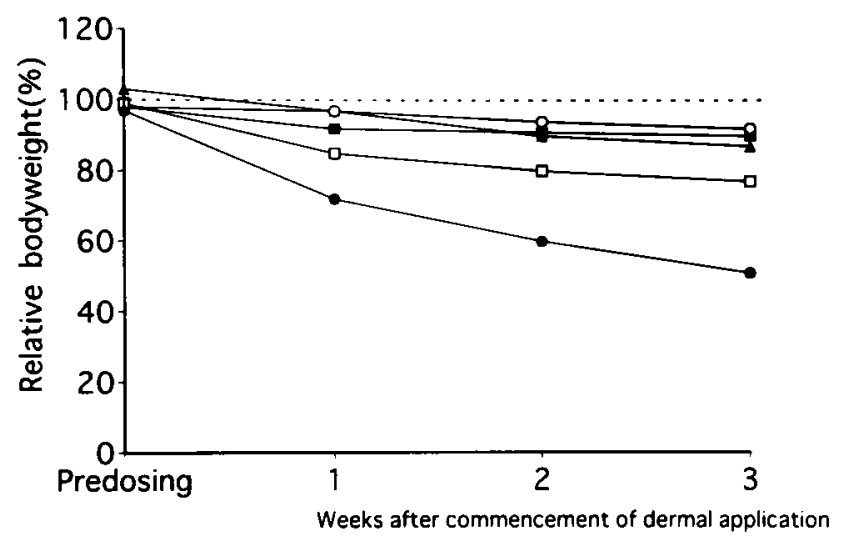

Fig. 1. Bodyweight.

Bodyweight was expressed as relative \% to that in sham control each week.

च : $0.3 \%$ FK 506, $\bullet: 0.05 \%$ clobetasol 17-propionate, $\triangle$ : $0.12 \%$ betamethasone 17 -valerate, $0: 0.05 \%$ clobetasone 17-butyrate, $\square: 0.5 \%$ prednisolone dilution $1: 100$ ). After washing, the slides were treated with labelled streptavidin-biotin kit (Dako LSAB2 kit, Carpinteria, CA, USA). The final reaction products were developed with $3,3^{\prime}$-diaminobenzidine tetrahydrochloride (DAB, Wako Pure Chemicals, Osaka, Japan) and the sections were lightly counterstained with hematoxylin.

\section{Statistical analysis}

Statistical comparison between sham control and ointment-treated groups was performed by the use of Dunnett's or Wholly significant difference test after analysis of variances.

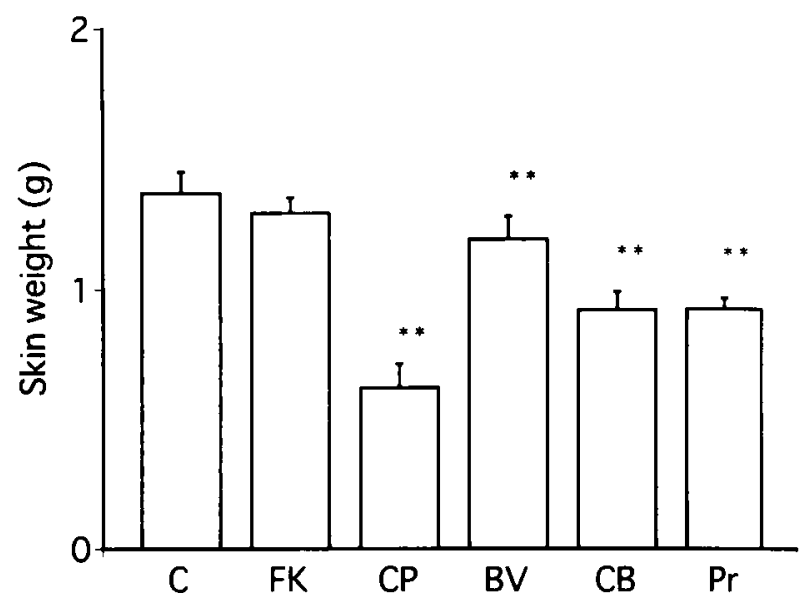

Fig. 2. Skin weight.

Skin of a 3 centimeters diameter circle punched from application site was weighed.

C: sham control, FK: $0.3 \%$ FK506, CP: $0.05 \%$ clobetasol 17 -propionate, BV : $0.12 \%$ betamethasone 17 valerate, $\mathrm{CB}: 0.05 \%$ clobetasone 17 -butyrate, $\mathrm{Pr}: 0.5 \%$ prednisolone.

Values are expressed as mean \pm S.D. $(n=6-7)$

${ }^{* *} \mathrm{P}<0.01$ : Statistically significant difference from sham control.

Table 1. Skin Thickness

\begin{tabular}{lcccc}
\hline \multirow{2}{*}{ Drug } & \multicolumn{4}{c}{ Skin thickness $(\mathrm{mm})$} \\
\cline { 2 - 5 } & Predosing & 1 week & 2 weeks & 3 weeks \\
\hline sham control & $1.71 \pm 0.11$ & $2.73 \pm 0.26$ & $2.97 \pm 0.21$ & $2.58 \pm 0.15$ \\
$0.3 \%$ FK506 & $1.72 \pm 0.16$ & $2.75 \pm 0.25$ & $2.88 \pm 0.19$ & $2.39 \pm 0.13^{*}$ \\
& & $(100.7)^{1)}$ & $(97.0)$ & $(92.6)$ \\
0.05\% clobetasol & $1.71 \pm 0.13$ & $1.50 \pm 0.09^{* *}$ & $1.23 \pm 0.11^{* *}$ & $1.10 \pm 0.07^{* *}$ \\
propionate & & $(54.9)$ & $(41.4)$ & $(42.6)$ \\
0.12\% betamethasone & $1.71 \pm 0.06$ & $2.56 \pm 0.15$ & $2.48 \pm 0.18^{* *}$ & $2.20 \pm 0.12^{* *}$ \\
valerate & & $(93.8)$ & $(83.5)$ & $(85.3)$ \\
0.05\% clobetasone & $1.71 \pm 0.08$ & $2.31 \pm 0.14^{* *}$ & $2.17 \pm 0.13^{* *}$ & $1.75 \pm 0.11^{* *}$ \\
butyrate & & $(84.6)$ & $(73.1)$ & $(67.8)$ \\
0.5\% prednisolone & $1.72 \pm 0.16$ & $1.99 \pm 0.24^{* *}$ & $1.90 \pm 0.23^{* *}$ & $1.63 \pm 0.15^{* *}$ \\
& & $(72.9)$ & $(64.0)$ & $(63.2)$ \\
\hline
\end{tabular}

\footnotetext{
Values are expressed as mean \pm S.D. $(n=6-7)$.

1) Relative \% to thickness in sham control

* $\mathbf{P}<0.05,{ }^{* *} \mathbf{P}<0.01$ : Statistically significant difference from sham control
} 


\section{Results}

\section{Bodyweight}

Bodyweight gain in the FK506 ointment group was slightly less than in the sham control group, while the pattern of bodyweight change in the $\mathrm{CB}, \mathrm{BV}$, and Prointment groups was similar to that in FK506 ointment. However, CP ointment caused a marked decrease in bodyweight gain; bodyweight in this group was about $50 \%$ of the sham control group at conclusion of application (Fig. 1).

\section{Skin thickness and its weight in topical sites}

The thickness of the skin treated with FK506 ointment was similar to that observed in the sham comtrol group in week 1 and 2, and though significant thinning was observed in week 3, the difference between the FK506 and sham control was very small. In contrast, skin thickness was significantly decreased in the $\mathrm{CP}, \mathrm{CB}$, and $\mathrm{Pr}$ ointment groups from week 1 , and in the $\mathrm{BV}$ ointment group from week 2 (Table 1). CP had the strongest atrophogenic potential. Beside skin thickness, skin weight was measured as an index
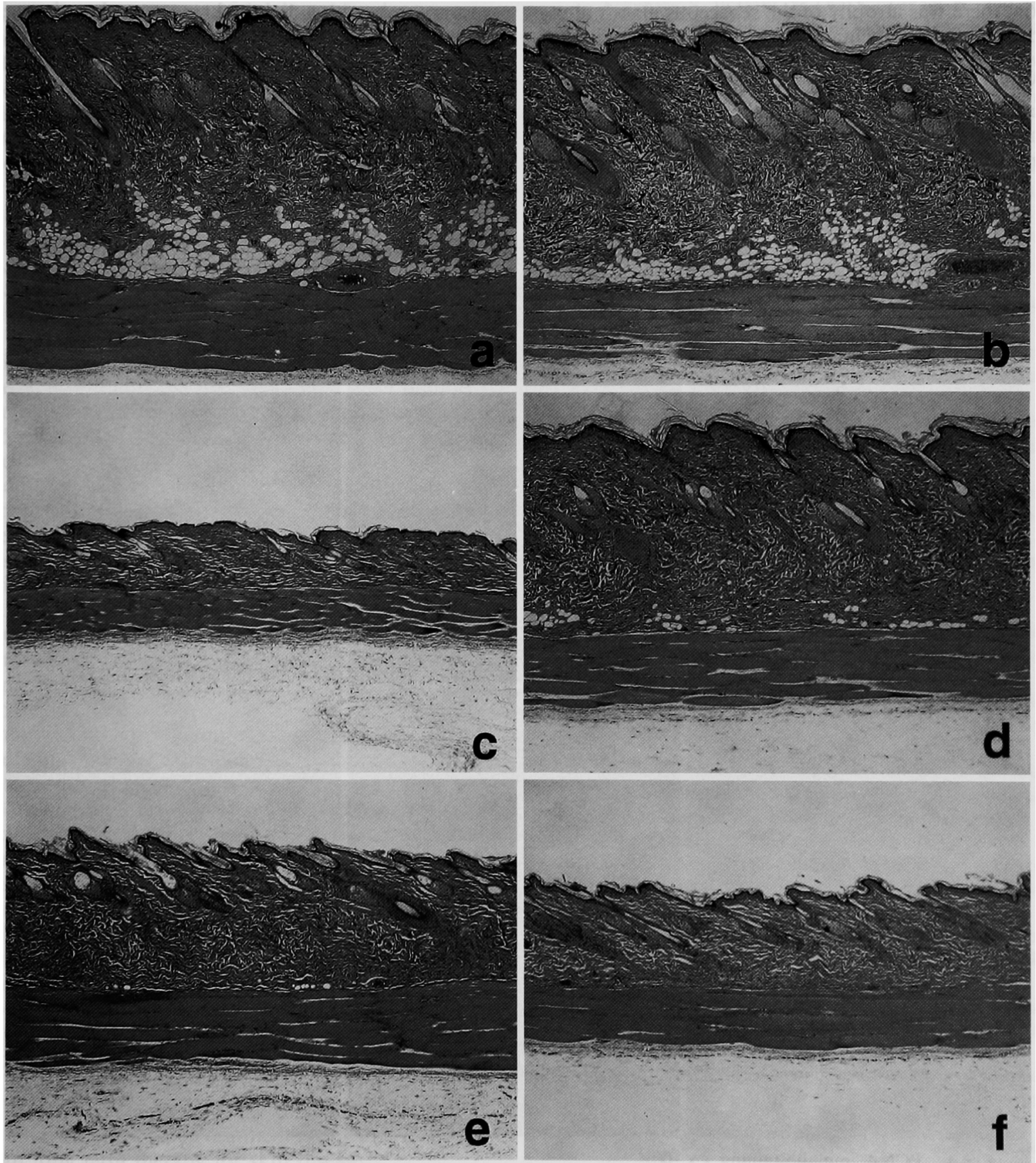

Fig. 3. Hematoxylin and eosin staining. $(\times 33)$

a : sham control, b : $0.3 \%$ FK 506, c : $0.05 \%$ clobetasol 17-propionate, $d: 0.12 \%$ betamethasone 17 -valerate, e : $0.05 \%$ clobetasone 17 -butyrate, $f: 0.5 \%$ prednisolone 
for estimating dermal atrophogenicity. The dermal atrophogenicity of FK506 ointment, derived from this index, was similar to that on the skin thickness: namely, no significant difference was observed in the skin weight between the FK506 group and the sham control, while that of the glucocorticoid groups decreased significantly compared with the sham control (Fig. 2).

\section{Histopathological examination}

$H \& E$ staining: The skin treated with FK506 ointment was histopathologically similar to that in the sham control group. In contrast, all of the glucocorticoid ointments decreased the subcutaneous fatty tissues, and CP, CB, and Pr ointments reduced the thickness of the epidermis and dermis. In addition, there was atrophy of the sebaceous glands along with thinning of the subcutaneous muscular layers in rats treated with CP ointment (Fig. 3).

$P C N A$ staining: PCNA positive nuclei were identified in epidermal and follicular basal epithelial cells of the FK506-treated rats with a similar frequency to that in the sham control group. A small number of PCNA positive cells were detected in the skin of the BV-treated rats, but none were seen in the $\mathrm{CP}, \mathrm{CB}$, or Pr-treated rats (Fig. 4).

\section{Discussion}

Several methods have been proposed for assessing the deŕmal atrophogenicity; direct measurement of skin thickness with a micrometer ${ }^{10,11}$ or dial thickness gauge ${ }^{14}$, weighing of skin disc ${ }^{15}$, histopathological examination ${ }^{16}$, and radiological techniques ${ }^{17,18}$.

Skin thickness has the advantage that its time course can be traced, while there is room as will for technical skills. Accordingly, for reliable estimation, we measured skin thickness not only with a dial thickness gauge but also weighed the skin discs in the present study. Since these two methods were well correlated, we considered them to be satisfactory methods for examining dermal atrophogenicity.

As a result, each of these methods showed that application of $0.3 \%$ FK 506 ointment for 3 weeks caused no dermal thinning. HE staining also revealed no abnormal changes

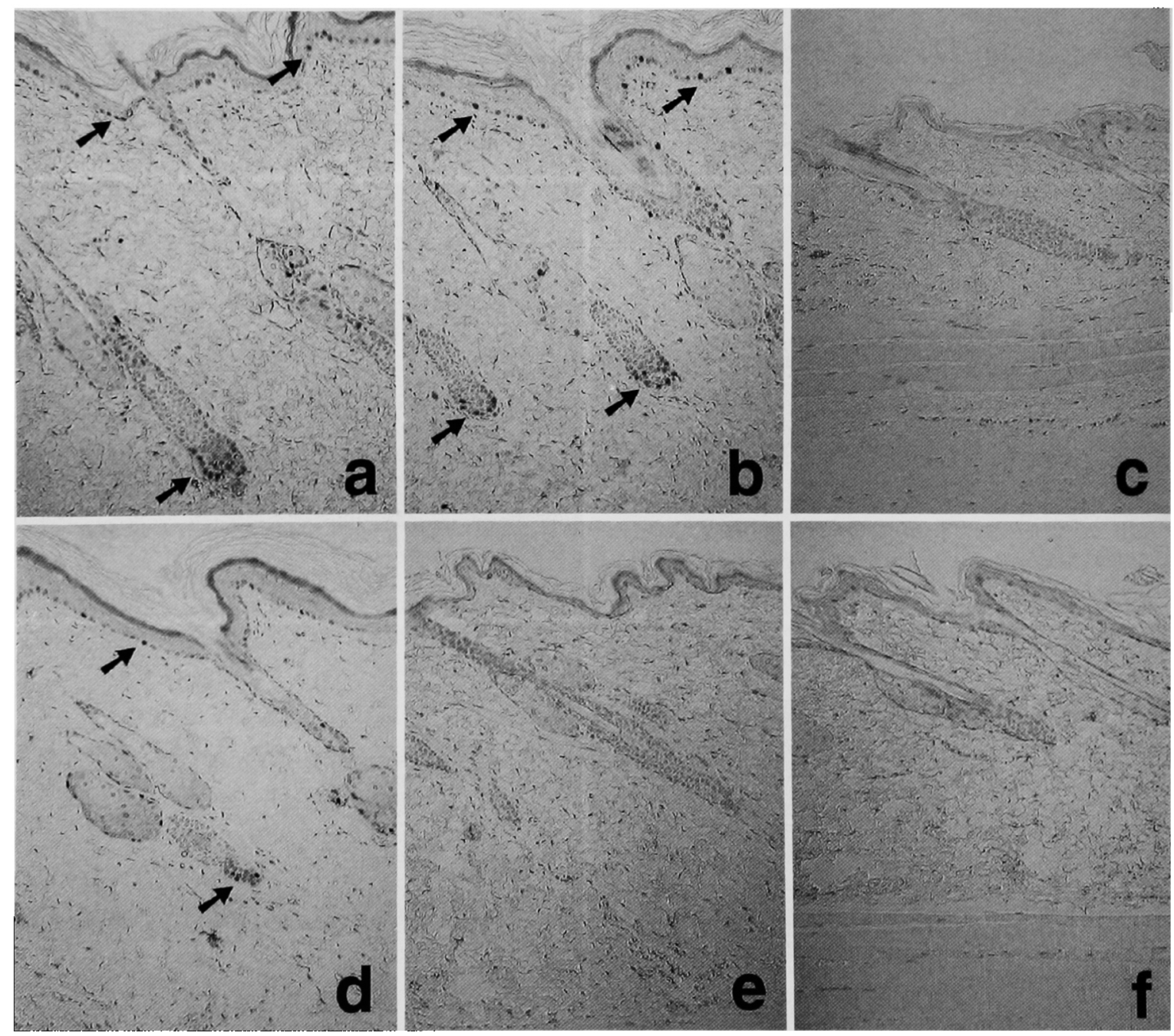

Fig. 4. PCNA immunostaining. $(\times 100)$

a : sham control, $b: 0.3^{\circ}$ FK $506, c: 0.05^{\circ}$ clobetasol 17-propionate, $d: 0.12 \%$ betamethasone 17 -valerate, e : $0.05 \%$ clobetasone 17 butyrate, $f: 0.5^{\circ} \%$ prednisolone Arrows $=$ PCNA positive cells 
in the skin, and additionally, PCNA immunostaining was positive in epidermal and follicular basal epithelial cells as well as in these parameters in the sham control group. Celis et $a l^{19}$ have reported that PCNA is an intranuclear polypeptide that is found in both normal and transformed proliferating cells, and its expression (positive in PCNA staining) means that cells have a proliferating potential. Thus, the results of the present study suggest that FK506treated epidermal cells could proliferate normally. Duncan et $a L^{20}$ have reported that FK 506 did not have an inhibitory effect on the proliferation of keratinocytes isolated from normal human pediatric foreskin when the keratinocytes were treated with $10-1,000 \mathrm{ng} / \mathrm{ml}$ of FK506. Their in vitro results are consistent with those in our present study.

Unlike FK506 ointment, glucocorticoid ointments induced skin atrophy, although the degree of atrophy did not completely correspond with the grade of clinical efficacy of the glucocorticoid ointments. An example of this difference was noted in BV ointment which had better clinical efficacy and less atrophogenic effect than $\mathrm{CB}$ or Pr ointment. This may reflect that the mechanism of expected pharmacological effect, for example anti-inflammatory action, may differ from that of skin atrophogenic action. Nomoto ${ }^{21}$ showed that $0.02 \%$ flumethasone 21-pivarate ointment (efficacy : medium), $0.1 \%$ triamcinolone acetonide ointment (efficacy: medium), and CP ointment have marked atrophogenicity, while $0.1 \%$ hydrocortisone 17-butyrate ointment (efficacy: medium) and BV ointment have mild atrophogenicity. In brief, while the efficacy of BV ointment is strong, its dermal atrophogenic potential is less than that of the other ointments which are only of medium efficacy. These observations are in accord with ours that show BV ointment has a weak atrophogenicity.

In addition to skin atrophy, the topical application of glucocorticoids suppressed bodyweight gain in rats suggesting that systemic toxicity may be involved in glucocorticoidinduced skin atrophy. Although the participation of systemic toxicity can not be denied, the skin atrophy induced by glucocorticoid ointment is considered to be at least partially due to its direct action on skin, because the correlation between the atrophogenic potential and the suppression of bodyweight gain for each glucocorticoid ointment did not always coincide.

Thinning of the epidermis and dermis along with a decrease of subcutaneous adipose tissue was observed in the skin treated with glucocorticoid ointments. Furthermore, PCNA positive cells were not found in the glucocorticoidtreated skin except in those exposed to BV ointment. These results suggest that the skin atrophy was induced by the decrease of adipose tissue due to the promotive effect of lipid metabolism and suppressive effect on the proliferation of the epidermal cells, both of which are distinctive characteristics of glucocorticoids.

In conclusion, it is evident that topical application of FK506 ointment to the skin of rats for 3 weeks did not induced skin atrophy, which is one of the characteristic dermal toxicities of glucocorticoid ointments in long term clinical application. Thus the atrophogenic potentials between FK506 ointment and glucocorticoid ointments are clearly established and FK506 ointment is expected to be well tolerated in long term therapy for skin disease.

\section{References}

1. Kino T, Hatanaka H, Hashimoto M, Nishiyama M, Goto T, Okuhara M, Kohsaka M. Aoki H, and Imanaka H. FK-506, a novel immunosuppressant isolated from a streptomyces. I. Fermentation, isolation, and physico-chemical and biological characteristics. J Antibiot 1987; 40: 1249-55.

2. Kino T, Hatanaka H, Miyata S, Inamura N, Nishiyama $M$, Yajima T, Goto T, Okuhara M, Kohsaka M, Aoki H, and Ochiai T. FK-506, a novel immunosuppressant isolated from a streptomyces. II. Immunosuppressive effect of FK-506 in vitro. J Antibiot $1987 ; 40:$ 1256-65.

3. Japanese FK506 study group (Ochiai T, Fukao K, Takahashi K, Endo T, Oshima S, Uchida K. Yokoyama I, Ishibashi M, Takahara S, Iwasaki Y, Ota K. Takagi H, and Sonoda T). Phase III study of FK506 in kidney transplantation. Transplant Proc 1995; 27 : 829-33.

4. The U.S. multicenter FK 506 liver study group. A comparison of tacrolimus (FK506) and cyclosporine for immunosuppression in liver transplantation. N Engl J Med 1994; 331 : 1110-15.

5. European FK506 multicentre liver study group. Randomised trial comparing tacrolimus (FK506) and cyclosporin in prevention of liver allograft rejection. Lancet $1994 ; 344$ : 423-28.

6. Nakagawa $H$, Etoh $T$, Ishibashi $Y$, Higaki $Y$, Kawashima $M$, Torii $\mathrm{H}$, and Harada S. Tacrolimus ointment for atopic dermatitis. Lancet $1994 ; 344: 883$.

7. Delforno C, Holt PJA, and Marks R. Corticosteroid effect on epidermal cell size. Br J Dermatol 1978; 98 : 619-23.

8. Dykes PJ, and Marks R. An appraisal of the methods used in the assessment of atrophy from topical corticosteroids. $\mathrm{Br} \mathrm{J}$ Dermatol 1979; 101 : 599-609.

9. Kohda H, Fukuda H, Hino $Y$, and Urabe $H$. Adverse effects of topical corticosteroids (in Japanese). Nishinihon J Dermatol $1978 ; 40: 177-87$.

10. Smith JG, Wehr RF, and Chalker DK. Corticosteroid-induced cutaneous atrophy and telangiectasia. Arch Dermatol 1976; 112 : 1115-17.

11. Kirby JD, and Munro DD. Steroid-induced atrophy in an animal and human model. Br J Dermatol 1976; 94 (suppl 12) : $111-19$.

12. Winter GD, and Wilson L. The effect of clobetasone butyrate and other topical steroids on skin thickness of the domestic pig. Br J Dermatol 1976; 94 : 545-50.

13. Takeda K. Topical corticosteroids and their evaluation (in Japanese). Rinsho Derma (Tokyo) 1984; 26 (suppl 24): 631-47.

14. Ikoma $\mathrm{Y}$, Yamashita $\mathrm{M}$, Kamitani $\mathrm{K}$, and Nakagawa $\mathrm{H}$. Anti-inflammatory, systemic and dermal atrophy activities in topical application of dermal methylprednisolone aceponate (in Japanese). Clin Rep 1991; $25: 2643-50$.

15. Young JM, Yoxall BE, and Wagner BM. Corticosteroidinduced dermal atrophy in the rat. J Invest Dermatol 1977: 69: $458-62$.

16. Marks R. Methods for the assessment of skin atrophogenicity of topical corticosteroids. Dermatologica 1976; 152 (Suppl 1): $117-26$.

17. Marks R, Dykes PJ, and Roberts E. The measurement of corticosteroid induced dermal atrophy by a radiological method. Arch Derm Res $1975 ; 253$ : 93-96.

18. Snyder DS, and Greenberg RA. Radiographic measurement of topical corticosteroid-induced atrophy. J Invest Dermatol 1977; 69: 279-81.

19. Celis JE, and Celis A. Cell cycle-dependent variations in the distribution of the nuclear protein cyclin proliferating cell nuclear antigen in cultured cells: subdivision of $S$ phase. Proc Natl Acad Sci USA 1985; 82 : 3262-66.

20. Duncan Jl. Differential inhibition of cutaneous T-cell- 
mediated reactions and epidermal cell proliferation by cyclosporin A, FK-506, and rapamycin. J Invest Dermatol $1994 ; 102$ : 84-88.

21. Nomoto $M$. In vitro and in vivo investigation of the effects of corticosteroids on the skin : with special reference to the relation between skin atrophy and DNA synthesis inhibition (in Japanese). Nishinihon J Dermatol 1981 ; 43 : 797-803. 